\title{
Teología feminista como instancia crítica de las religiones en el espacio público. La propuesta de Elisabeth Schüssler Fiorenza
}

\author{
Feminist theology as critical reinforcement of reli- \\ gions in the public sphere. \\ Elisabeth Schüssler Fiorenza's proposal
}

\author{
MONTSERRAT ESCRIBANO CÁRCEL \\ Universitat de València (España)
}

Recibido: 6-1-2012

Aprobado definitivamente: $30-1-2012$

\section{RESUMEN}

Este artículo se acerca al papel público que las religiones desempeñan en las democracias. Para ello es necesario que cultiven un doble afán. El primero, que mira hacia el exterior y sitúa a la religión católica entre el resto de esferas que definen nuestras sociedades plurales. El artículo cuestiona la tarea ética que puede ejercer esta tradición religiosa y que ha de reforzar el marco democrático en el que todas estas esferas se incluyen. El segundo, que mira hacia el interior de esta religión y ocupa la mayor parte de este artículo, gira en torno a la teología feminista desarrollada por Elisabeth Schüssler Fiorenza. Su sentido crítico está transformando la identidad 
de los y las creyentes, los horizontes comprensivos religiosos y puede ayudar así a reforzar el papel de las democracias.

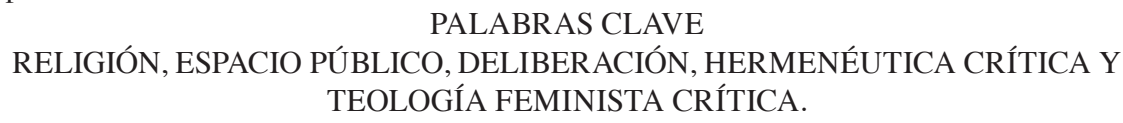

PALABRAS CLAVE

RELIGIÓN, ESPACIO PÚBLICO, DELIBERACIÓN, HERMENÉUTICA CRÍTICA Y TEOLOGÍA FEMINISTA CRÍTICA.

\begin{abstract}
This article approaches the public part religions play in democracies. On the one hand, the Catholic religion has to be set amidst the rest of the spheres, which define our plural societies. In this first part, we will try to evaluate how the Catholic religion helps reinforcing the democratic frame in which it evolves. On the other hand, the largest part of this article will be devoted to the Catholic feminist theology developed by Elisabeth Schüssler Fiorenza not only as a means of changing the identity of believers and their understanding religious horizons, but also as a way of strengthening the role of democracies.
\end{abstract}

KEYWORDS

RELIGION, PUBLIC SPHERE, DELIBERATION, CRITICAL HERMENEUTICS AND CRITICAL FEMINIST THEOLOGY

\title{
I. INTRODUCCIÓN
}

LAS SOCIEDADES DEMOCRÁTICAS ESTABLECEN EL MARCo en el que el espacio público se convierte en un ámbito de encuentro de las distintas esferas y concepciones que la forman. En ellas están inscritas también las religiones, tradiciones religiosas y las espiritualidades alternativas. Este marco, que debe ser amplio, aspira a que cada una de las esferas que alberga pueda desarrollarse de manera relacional y ejercer a su vez, con independencia, la función que le es propia. Sin embargo, el marco democrático también puede servir al mismo tiempo de interrogante para las instituciones que tienen lugar en su interior, incluidas también las religiosas. Esta es una de las tareas claves que la teología feminista como instancia crítica está realizando en la iglesia católica. Así plantea interrogantes que cuestionan el modo en el que es elaborado el conocimiento teológico, sospecha de la comprensión tradicional de los textos bíblicos, y reclama el establecimiento de espacios democráticos en donde se reconozca a todos sus miembros como sujetos deliberativos. Esta teología crítica es consciente de los problemas que de aquí se derivan para el conjunto de la vida social, sabiendo el lugar central que ocupan en la identidad, personal y grupal de las personas en el espacio público. Su actuación traza dos direcciones hacia el interior mismo de la religión católica y también hacia su exterior, atendiendo a su influencia 
sobre la sociedad.Es por ello pertinente cuestionarnos el papel ético que pueden desempeñar las religiones dentro del marco establecido por las sociedades que aspiran a ser democráticas.

\section{LA TAREA ÉTICA DE LAS RELIGIONES EN EL ESPACIO PÚBLICO}

Las confesiones mayoritarias, las distintas tradiciones religiosas y las espiritualidades alternativas que están surgiendo, lejos de perder actualidad, como se auguraba tras la Ilustración, continúan teniendo una vitalidad poco imaginable en aquel momento. Desde finales del siglo XX asistimos a un proceso de «desprivatización» de las religiones en el que se rechaza el papel marginal e íntimo, augurado por las teorías de la modernidad y las teorías de la secularización. En la actualidad su labor, lejos de ser irrelevante, se muestra como una condición política necesaria pues genera tomas de postura y modela identidades. Esto sucede no únicamente en el ámbito privado de los sujetos creyentes, sino también en la esfera pública de las sociedades civiles. Así José Casanova señala que:

En todo el mundo las religiones van adentrándose en la esfera pública y en la escena de la controversia política no sólo para defender su territorio tradicional, como hicieron en el pasado, sino también para participar en las mismas luchas por definir y establecer los límites modernos entre las esferas pública y privada, entre el sistema y la vida contemporánea, entre la legalidad y la moralidad, entre el individuo y la sociedad, entre la familia, la sociedad civil y el Estado, entre las naciones, estados, civilizaciones y el sistema mundial. ${ }^{1}$

Las religiones y tradiciones -tanto espirituales como religiosas- son hoy una fuente de sentido en el interior de las democracias modernas. Su capacidad para «lo político» radica en su posibilidad de significación y de interpretación de la realidad que ofrece un sentido trascendente al ser humano respetando los límites de las leyes legítimas de cada Estado. Además de ofertar una orientación ante las cuestiones últimas de la persona, la identidad religiosa es también un modo profundamente arraigado para determinar su subjetividad. Estamos asistiendo, en nuestras sociedades plurales, a la creación de nuevos modos de expresión de lo religioso, de lo celebrativo y de búsqueda de otros posibles cauces lingüísticos que canalicen de modo significativo nuestra necesidad espiritual y de sentido. Este dinamismo está traduciéndose en nuevas propuestas religiosas que exceden el espacio de las religiones tradicionales y ponen en cuestión sus

1 J. Casanova, Religiones públicas en el mundo moderno. Madrid: PPC, 2000, pp. 1618. 
instituciones. A ello hay que sumar también los compromisos éticos de todas aquellas personas que no confiesan ningún credo religioso.

De este modo, a nuestro alrededor florecen una pluralidad de formas espirituales y de distintas conciencias éticas que conviven a su vez con prácticas religiosas que no están ya circunscritas a los recintos ofertados por las religiones tradicionales, sino que exceden sus fronteras. El resultado es que las distintas formas y posibilidades de lo religioso, espiritual y secular generan un abanico, cada vez más amplio, de identidades personales y grupales variadas y frágiles que interactúan dentro del espacio público. El reto es buscar modelos que protejan, como señala Amy Gutmann, «la libertad de perseguir los compromisos éticos de cada uno, dentro de los límites de las leyes legítimas». ${ }^{2}$ Este es actualmente uno de los mayores desafíos a los que hemos de atender si queremos establecer marcos democráticos en los que se refuerce la autonomía, la libertad, el reconocimiento y la participación de grupos de identidades diferentes. A la vez, también han de salir fortalecidas las experiencias de justicia y de gobierno para todas las personas, desde el compromiso de todas las esferas que actúan en nuestras sociedades plurales y que han de trazar marcos éticos que permitan la presencia del juego democrático en su interior.

\section{LAS RELIGIONES COMO INSTANCIAS CRÍTICAS. \\ EL PAPEL DE LA TEOLOGÍA FEMINISTA CRÍTICA}

El sentido último de nuestras vidas y nuestra conciencia ética es normativo. Así, la irrupción de las religiones en la vida sociopolítica puede convertirse en una instancia crítica que fortalezca nuestras sociedades laicas y sus procesos democratizadores y fecunde la vida política y los procesos deliberativos ante la pluralidad de las concepciones de justicia. ${ }^{3}$ Pero teniendo siempre presente que la fe o las creencias religiosas no pueden ser el fundamento único para la creación de las leyes comunes en los estados laicos. Sin embargo, sí resulta que las religiones y confesiones, lejos de quedar reducidas al ámbito privado, están llamadas en la actualidad a convertirse en herramientas éticas. Estas podrían ser virtudes epistémicas, que ayuden a alcanzar una mayor justicia democrática, que suponga tratar «a todos los individuos según los principios de igualdad civil y de iguales libertades y oportunidades». ${ }^{4}$

2 A. Gutmann, La identidad en democracia. Buenos Aires: Katz, 2008, p. 267.

3 Cf. R. Díaz-Salazar, Democracia laica y religión pública. Madrid, Taurus: 2007, pp. 39-45.; Ver también: España laica. Ciudadanía plural y convivencia nacional, Madrid: Espasa: 2008; «El laicismo en España: corrientes internas y tendencias ideológicas». Estudios Eclesiásticos, 86 (2011), pp. 329-341; R. Díaz-Salazar, T. González, R. Mate, A. Ollero y J. Mayorga, Religión y laicismo hoy, Madrid: Anthropos, 2010.

4 A. Gutmann, La identidad en democracia, op. cit., p. 269. 
De ahí que la necesaria convivencia, de las distintas cosmovisiones, conciencias éticas y cuestiones últimas de la vida que comparten el interior de la esfera pública pueda ser también un estímulo ético para las religiones en nuestros días. Su tarea crítica podría ser una de las labores más interesantes para la construcción de nuestras democracias maleables, falibles y transformables. Por ello, la incorporación de instituciones religiosas dispuestas a colaborar de modo creativo en la vida política puede tener al menos dos consecuencias para la racionalidad de la modernidad crítica. La primera es que los y las creyentes pueden aportar los valores, el lenguaje y la experiencia de su propia tradición religiosa. Esta consecuencia ha sido estudiada últimamente por filósofos dispares como Jürgen Habermas, ${ }^{5}$ Gianni Vattimo, ${ }^{6}$ René Girard ${ }^{7}$ y otros más reacios como Richard Rorty ${ }^{8}$ Jacques Derrida ${ }^{9}$. En el ámbito estatal también filósofas como Victoria Camps,${ }^{10}$ Amelia Valcárcel ${ }^{11}$ o Adela Cortina ${ }^{12}$ se han ocupado de reflexionar sobre estas cuestiones. La segunda de estas consecuencias y quizá menos reflexionada, consiste en que, al quedar expuestas las religiones en el espacio público, pueden también ellas mismas sentirse interpeladas por otras tradiciones religiosas, culturales, jurídicas, científicas o democráticas con las que conviven dentro de las sociedades civiles. De ahí que los y las creyentes lancen, de modo reflejo, sus interrogantes también hacia el interior de las instituciones a las que se sienten vinculados y de las cuales demandan respuestas significativas y éticas. A esta última consecuencia pretendo acercarme en este artículo.

Esta reflexión crítica fue abordada desde el ámbito de la filosofía de la religión y desde el espacio de la sociología, aunque, últimamente, lo está asumiendo también la disciplina teológica. Sus inicios pueden rastrearse ya en los

5 J. Habermas, Entre naturalismo y religión. Barcelona: Paidós, 2006; J. Habermas y J. Ratzinger, Dialéctica de la secularización. Sobre la razón y la religión. Madrid: Encuentro, 2006; J. Habermas, «La voz pública de la religión. Respuesta a Flores d'Arcais», Claves de razón práctica, 180 (2008), pp. 4-12; J. Habermas, Ch. Taylor, J. Butler y C. West, El poder de la religión en la esfera pública. Madrid: Trotta, 2011.

6 G. Vattimo, Después de la cristiandad. Por un cristianismo no religioso. Barcelona, Paidós, 2003; G. Vattimo [et al.], Politeísmo y encuentro con el Islam. Madrid: Dykinson, 2008; Adiós a la verdad. Barcelona: Gedisa, 2010.

7 R. Girard y G. Vattimo, ¿ Verdad o fe débil? Diálogo sobre cristianismo y relativismo. Barcelona: Paidós, 2011.

8 R. Rorty y G. Vattimo, El futuro de la religión. Solidaridad, caridad, ironía. Barcelona: Paidós, 2006.

9 J. Derrida y G. Vattimo (dirs.): La religión. Madrid: PPC, 1996; J. Derrida, J.: Dar la muerte. Barcelona: Paidós, 2000.

10 V. Camps y A. Valcárcel, Hablemos de Dios. Madrid: Taurus, 2007.

11 A. Valcárcel, La memoria y el perdón. Barcelona: Herder, 2010.

12 A. Cortina, La ética de la sociedad civil. Madrid: Alauda/Anaya, 1994; Ética civil y religión. Madrid: PPC, 1995; Alianza y Contrato. Madrid: Trotta, 2001. 
años 70 del pasado siglo cuando esta tarea comenzó a ser desempeñada, con determinación, por algunas teólogas feministas. Nos referimos en este artículo solamente a las que pertenecen a la tradición cristiana. Su esfuerzo teológico gravitó desde entonces alrededor de varios puntos focales: recuperar el papel que las mujeres tuvieron desde los inicios en su tradición religiosa y descubrir la riqueza que ello supone; elaborar herramientas metodológicas que permitan acercarse al hecho religioso desde claves comprensivas feministas; poner en valor su producción intelectual que dista de aquella otra realizada por los teólogos varones; elaborar un corpus teológico que pueda ser reconocido como autorizado y en el que las interpretaciones bíblicas, doctrinales y prácticas litúrgicas sean legitimadas. Todo ello dentro del marco trazado por una disciplina académica, como es la teología, con una tradición casi exclusivamente masculina que ha ocultado y silenciado sistemáticamente «otros» puntos de vista diferentes de los propios y que se ha negado reiteradamente a tenerlos en cuenta, calificándolos de no autorizados. Frente a ello la teología feminista está actuando como instancia crítica dentro de su propia tradición.

\section{REPENSAR LA RELIGIÓN CATÓLICA EN EL ESPACIO PÚBLICO DE LAS SOCIEDADES DEMOCRÁTICAS}

Las peticiones de sentido y de reconocimiento recíproco, ${ }^{13}$ a la vez personales e institucionales, que plantean los y las creyentes en la actualidad hunden sus raíces en los acontecimientos culturales, históricos y políticos de los que forman parte. Las sociedades, llamadas occidentales, son complejas y pluriformes, necesitadas, cada vez más, de métodos deliberativos que permitan poner en diálogo las distintas propuestas creyentes y no creyentes que transitan en ellas, pues todas reclaman sus derechos dentro del ámbito público y éste ha de ser compartido por todos. Al mismo tiempo, las confesiones religiosas a través de sus prácticas, ritos, imaginarios religiosos y textos considerados sagrados son productoras de identidades creyentes.

En este proceso, los sujetos implicados van teniendo una mayor conciencia de la necesidad de formar parte activa de esta creación que afecta, de primera mano, a su propia intimidad pero que también queda expuesta a través de la convivencia con el resto de individuos - creyentes y no creyentes- con los que comparte su vida diaria. Por ello, las peticiones legítimas de otros posibles sentidos y de reconocimiento, en el interior mismo de las iglesias se están comenzando a sentir con fuerza. Adquieren, estas reivindicaciones, como en el caso de la teología feminista católica, aún mayor legitimidad cuando se plantean dentro del marco de las sociedades democráticas en las que comparten el espacio

13 Cf. A. Honneth, Reconocimiento y menosprecio. Sobre la fundamentación normativa de una teoría social. Madrid: Katz, 2010. 
público. ${ }^{14}$ Este marco comprensivo, que aspira a ser democrático, empuja a la teología feminista católica a reclamar que a todos los y las creyentes les sean reconocidos sus derechos, especialmente, aquellos que afectan directamente a su tradición religiosa. El deseado reconocimiento implicaría así la creación de espacios dentro de la iglesia católica en donde sus voces pudieran ser escuchadas y en los que todos los implicados pudieran participar de manera plena en la toma de decisiones.

La ausencia de estos espacios de deliberación y el no reconocimiento de muchos de sus miembros -mujeres, sacerdotes secularizados, divorciados/as, gays, lesbianas o transexuales- como «interlocutores válidos», recurriendo a la terminología de la Escuela de Frankfurt y de las teorías políticas de la deliberación, pone en cuestión si la religión cristiana está cooperando, o no, en la tarea de alentar, sostener y promover los ejes centrales sobre los que las sociedades democráticas se sostienen. Estos podrían ser el gobierno del pueblo y la representación de sus ciudadanos y ciudadanas. Ejes que apuntalan los valores esenciales que orientan nuestras sociedades como son: la libertad, la autonomía, la civilidad, la agencia, la dignidad humana o la necesidad moral de reconocimiento. Por ello, interrogarnos sobre estas cuestiones es pertinente si consideramos el papel que hoy desarrolla la religión católica dentro del ámbito público.

Acotando la cuestión algo más y sirviéndonos de los procedimientos de la ética del discurso, podríamos plantearlo del siguiente modo: puesto que la iglesia católica incide en el ámbito público dentro del marco de las sociedades democráticas ¿debería esta tomar sus decisiones de modo ético, es decir, reconociendo a todos y cada creyente como un interlocutor válido?, ¿considera la iglesia católica a todos sus miembros como interlocutores válidos a la hora de la toma de decisiones?, ¿son las mujeres dentro de la iglesia católica reconocidas como miembros partícipes de una comunidad de hablantes?, ¿podemos valorar como éticas algunas de las propuestas morales elaboradas por la iglesia católica y que nacen con pretensión de validez universal, mientras esta sigue sin reconocer como sujetos de pleno derecho a la mayoría de sus creyentes por razón de su sexo, orientación sexual, etnia o condición social?, ¿pueden o deberían demandar las personas o grupos que son alejados de modo sistemático de la toma de decisiones, ser reconocidas como sujetos de la comunidad interpretativa que es la iglesia católica? y, ¿podrían darse espacios democráticos deliberativos y emancipadores dentro de la iglesia católica?

14 Cf. J. Habermas, «Lo político: el sentido racional de una cuestionable herencia de la teología política», en J. Habermas, Ch. Taylor, J. Butler y C. West, El poder de la religión en la esfera pública, op. cit., pp. 23-38. 
La teología feminista crítica ha supuesto una disrupción en el pensamiento teológico y ha puesto en evidencia su responsabilidad política tanto con la sociedad civil como con los propios miembros que la componen. Este proceso cognoscitivo ha necesitado de mujeres que lo pusieran en marcha. Una de estas pioneras es la teóloga Elisabeth Schüssler Fiorenza.

\section{La Propuesta teológica de Elisabeth Schüssler Fiorenza}

Las teorías científicas, como mostró Thomas Samuel Kuhn, se adaptan a un paradigma de enfoque que establece los métodos, los problemas y las normas de resolución más apropiadas y cuyos resultados son aceptados por cualquier comunidad científica. ${ }^{15}$ De ahí el empeño de la teóloga feminista Elisabeth Schüssler Fiorenza en señalar, comprender y transformar una metodología de trabajo y una búsqueda de expresiones lingüísticas, interpretativas o celebrativas que nos permitan tomar conciencia y comprometernos con una metodología de trabajo que responda a otros paradigmas retórico-emancipadores que aspiren a ser más éticos. ${ }^{16} \mathrm{Su}$ propósito es manifestar la necesidad de espacios deliberativos en los que encontrar posibles soluciones liberadoras que, a través de un proceso dialógico analicen, de modo crítico, la reflexión y los intereses con los que llevamos a cabo nuestra producción de conocimiento dentro de los estudios bíblicos y la teología católica. Su objetivo último es el de aliviar a aquellos y aquellas que han sufrido y sufren todo tipo de opresiones a nuestro alrededor. Quizá, al acercarnos a esta propuesta metodológica podamos descubrir también si es posible establecer formas deliberativas dentro de la «comunión» a la que aspira la iglesia católica.

Elisabeth Schüssler Fiorenza nació en 1938, en Tschand, Rumanía. Tras el estallido de la Segunda Guerra Mundial su familia se trasladó, buscando un lugar seguro, primero a Austria y después a la zona alemana de Baviera, concretamente, a la ciudad de Weilbach. Allí cursó su formación inicial. Más tarde comenzó los estudios teológicos en la Julius-Maximilians-Universität de Wurzburgo, siendo la primera mujer en obtener la Licenciatura en Teología, en 1963 y la primera también que intentó realizar un doctorado en esa universidad, aunque no le fue permitido. Pasó entonces a formar parte del departamento intertestamental de estudios bíblicos de la Universidad Münster, especializándose en Testamento cristiano. En el año 1970, se trasladó hasta la Universidad de Notre Dame, en Estados Unidos, para poder desarrollar su vocación investigadora y educativa dentro del ámbito de la teología, pues en Europa no era posible

15 Cf. T. S. Kuhn, T. S, La estructura de las revoluciones científicas. Madrid: Fondo de Cultura Económica, 1994.

16 Cf. E. Schüssler Fiorenza, Apocalipsis. Visión de un mundo justo. Estella: Verbo Divino, 2003. 
en ese momento. Después de desarrollar su carrera profesional en diferentes universidades estadounidenses -Union Theological Seminary de Nueva York y Episcopal Divinity School en Cambridge- es en la actualidad, catedrática Krister Stendahl de la Harvard Divinity School. Fue además la primera mujer presidenta de la Society of Biblical Literature. Pertenece también a la American Academy of Arts and Sciences desde 2001 y, ha sido cofundadora de varias revistas, como la Journal of Feminist Studies in Religion. ${ }^{17}$

En los Estados Unidos, a partir de los años 60 y 70 del siglo XX, los movimientos de mujeres ganaron fuerza $\mathrm{y}$, junto con otras corrientes activistas, lograron despertar las conciencias de los y las ciudadanas, haciendo que se levantaran a favor de la ecología, de las protestas en contra de la Guerra de Vietnam, de la discriminación sexual y antisegregacionista, y de una mayor demanda de derechos civiles para los homosexuales. ${ }^{18}$ Este contexto interpeló a Schüssler Fiorenza tras su llegada a los Estados Unidos y le hizo virar su pensamiento hacia la elaboración de una teológica crítica feminista que plasmó en una de sus primeras obras clave: En memoria de ella. Una reconstrucción teológica-feminista de los orígenes del cristianismo.

La concepción del feminismo de esta teóloga parte de una verdad moral: todas las personas poseen valor y dignidad por sí mismas y no por comparación a otras. Esta verdad contrastaba con las relaciones de marginación y dominación que Schüssler Fiorenza descubrió en la realidad académica que le envolvía y que también padeció en primera persona. La experiencia de contradicción entre su propia vivencia intelectual y los valores de igualdad que mostraban los textos bíblicos le llevó a indagar sobre las causas por las que se establecían las relaciones asimétricas entre los seres humanos. Buscó también algunos procedimientos correctivos a un sistema de producción de conocimiento que resultaba opresor para las mujeres y para todos aquellos que biopolíticamente son considerados como «no-personas». ${ }^{19}$

Su propuesta fue desarrollar una hermenéutica atenta y una retórica crítica, diferente a la elaborada desde perspectivas masculinas-mayoritarias. Enfoques éstos que calificó de sesgados y condicionados ya que, históricamente, fueron planteados por élites de varones blancos con la pretensión de convertirse en universales y asumidos acríticamente por el resto. Schüssler Fiorenza mostró que

17 Cf. F. Segovia, (ed.): Toward a New Heaven and a New Earth. Essays in Honour of Elisabeth Schüssler Fiorenza. Maryknoll: Orbis Books, 2003, pp. 1-30.

18 Cf. E. Schüssler Fiorenza, Transforming Visions. Explorations in Feminist The*logy. Mineápolis: Fortress Press, 2011.

19 El término «no persona» es definido como aquel «insignificante», como alguien a quien no se le reconoce la plenitud de sus derechos. Se compara con las personas pobres que no tienen peso social o individual y por lo tanto resultan invisibles. Cf. R. Mate, Responsabilidad histórica. Preguntas del nuevo al viejo mundo. Barcelona: Anthropos, 2007, p. 35. 
estos puntos de vista resultaban reduccionistas también para los estudios bíblicos y teológicos. El saber teológico funcionaba, tradicionalmente, produciendo modos de lectura que, bajo la pretensión de responder a enfoques científicos, sostenían y alentaban posturas políticas colonialistas, sexistas, homofóbicas o bélicas. Estos enfoques, que aún permanecen activos, se desarrollan bajo el amparo de una comprensión excesivamente estrecha de los textos bíblicos considerados revelados y de la propia Tradición de la iglesia católica. En ella se selecciona a ciertos miembros -varones célibes que forman parte de la cúpula eclesiástica- que son autorizados para poder ejercer la interpretación textual y transmitir de modo legítimo la doctrina católica al resto de fieles que, a su vez, reciben esta enseñanza sin posibilidad de intervenir en este proceso. Esta producción de conocimiento se realiza, por tanto, en una única dirección y entorpece, enormemente, cualquier ejercicio deliberativo. De ahí que Elisabeth Schüssler Fiorenza señale la necesaria creación de posibles espacios democráticos donde los creyentes, principalmente las mujeres y los grupos minoritarios, puedan ser reconocidos como interlocutores válidos en el seno de la iglesia católica.

Schüssler Fiorenza, desde claves surgidas de las teorías feministas, elabora un planteamiento pionero que podemos resumir en tres momentos: evaluación, reconstrucción e imaginación. Vuelca esta metodología sobre su ámbito específico de investigación, el Testamento cristiano, pero teniendo como trasfondo la afirmación feminista de los años 60 de que: «todo lo personal es político». A este ensanchamiento de los horizontes políticos, Schüssler Fiorenza añadió el papel decisivo que la Biblia ha desempeñado en la vida de muchas personas y que determinó el modo antropológico por el que durante generaciones se comprendió a la divinidad, a la sociedad y al ser humano mismo.

\section{EL MOMENTO DE LA EVALUACIÓN: VER Y NOMBRAR}

Su propuesta parte de una necesaria revisión de los paradigmas de enfoque a los que recurrimos cuando interpretamos un texto. Afirma que toda interpretación conlleva una comprensión del texto y que ésta es determinada. Pues, partimos de un ethos común, es decir, de una comunidad de lectores, de oyentes y de observadores que comparten unos «regímenes de verdad». ${ }^{20}$ Así, al leer los textos lo hacemos desde unas convicciones de lectura previas que nos han sido inculcadas y que permanecen en el tiempo a través de creencias no siempre críticas. Su propuesta metodológica feminista es analizar las relaciones sociopolíticas que intervienen en este proceso interpretativo, determinar cuáles son las estrategias de lectura, tomar conciencia de las funciones políticas, de cuál es su influencia sobre nosotros y valorar sus consecuencias éticas. Para

20 Cf. M. Foucault, Power/Knowledge. Nueva York: Pantheon Books, 1980. 
ello, echó mano de distintos métodos hermenéuticos, que únicamente puedo apuntar en este trabajo, y son los siguientes:

1. Hermenéutica de la sospecha: método que pone en cuestión la literalidad textual y el positivismo histórico con que son leídos y trasmitidos los textos bíblicos. El objetivo es descubrir las funciones ideológicas que desempeñan y descubrir las estructuras de dominación inscritas en estos textos, en nuestras experiencias y en los contextos contemporáneos de interpretación.

2. Hermenéutica de la experiencia: intenta poner de manifiesto la importancia cognoscitiva de la experiencia humana como fuente de conocimiento. El criterio del cual parte son las experiencias socioculturales y religiosas de las personas marginalizadas y tradicionalmente excluidas.

3. Hermenéutica de la dominación y la ubicación social: trata de desvelar el kyriarcado ${ }^{21}$ como sistema socio-político multiplicativo de dominación y así fomentar la justicia y la liberación a través del potencial ofrecido por los textos bíblicos.

Esta teóloga feminista evidencia que la lectura que realizamos de la Biblia es resultado del fundamentalismo masculino-autoritario imperante que da paso a ideologías de sumisión y que sostiene, a menudo, actuaciones biopolíticas. Su propuesta tiene como punto de partida las experiencias de las mujeres y de las víctimas. Pero advierte que no son entendidas desde su ubicación social, por las cuales definimos comúnmente a las mujeres con denominaciones como: latinoamericanas, negras o españolas. Sino que han de ser evaluadas dentro de la compleja organización social en la que todos estamos inmersos y que está sostenida por relaciones de poder y de sometimiento que interaccionan constantemente entre sí. El resultado -elaborado desde este análisis sistémico- es un entramado complejo de relaciones socio-políticas que son no solo acumulativas,

21 El kyriarcado es un neologismo acuñado por Elisabeth Schüssler Fiorenza construido a partir de los términos kyrios (señor o maestro) y archein (gobernar o dominar) con la intención de resignificar la categoría de patriarcado y así incluir el complejo sistema de relaciones multiplicativas que se dan en las estructuras de dominación. Su interés es evidenciar el funcionamiento de las relaciones de poder y sometimiento, como identidades socialmente asignadas, tales como el sexo, la nacionalidad o la etnia. Cf. E. Schüssler Fiorenza, Los caminos de la Sabiduría. Maliaño: Sal Terrae, 2004. Ver también: E. Schüssler Fiorenza, «Introduction: Exploring the Intersections of the Race, Gender, Status, and Ethnicity in Early Christian Studies», en: L. Nasrallah y E. Schüssler Fiorenza (eds.): Prejudice and Christian Beginnings. Investigating Race, Gender, and Ethnicity in Early Christian Studies. Mineápolis: Fortress Press, 2009, pp. 1-26. 
sino multiplicativas en la vida de las personas. Schüssler Fiorenza define estas relaciones con el término kyriarcal, pues está persuadida de que éstas relaciones, resultan dominantes para las mujeres, operando a través de la segregación y de la identificación emocional.

Examinó en sus obras a) las modernas estructuras políticas de la dominación y de la ubicación social; b) las estructuras kyriarcales de la antigüedad inscritas en los textos bíblicos; y c) los modos de participación personal en estas relaciones kyriarcales.

La comprensión de este complejo sistema, central para entender el lugar ocupado por las mujeres a lo largo de la historia de la iglesia, le llevó a afirmar que una de las prioridades de esta institución fue mantener una posición asimétrica entre los seres humanos.

\section{EL MOMENTO DE RECONSTRUCCIÓN}

Schüssler Fiorenza advierte de que el «método dualista», a través del cual tradicionalmente se produce el conocimiento teológico, se adecua a las creencias sostenidas por la mayoría y su objetivo final es reforzarlas. Por ello, en su lugar propone valerse de un «método dialógico» aplicado a la historia del cristianismo inicial. Este método, que ella llama de reconstrucción, consiste en: hacer una evaluación crítica de los lugares en los que aparecen las mujeres a lo largo de los textos bíblicos, pero utilizando otras lentes. Es decir, otros marcos de sentido que permitan un deslizamiento del significado de estos textos bíblicos. Así, situándose desde otras estrategias de lectura, puede variar significativamente nuestra comprensión y descubrir significados nuevos que enriquezcan esta disciplina. Con ello no persigue evidenciar aquellos lugares silenciados reservados a las mujeres a lo largo de la historia, sino capacitarlas como sujetos históricos válidos que han producido su propio conocimiento. Schüssler Fiorenza no intenta, simplemente, sumar capítulos a los ya existentes en la historia pero esta vez en los que se mencione a las mujeres anteriormente silenciadas, sino comprender las luchas y esfuerzos llevados a cabo por estas mujeres y legitimarlos como una parte esencial de la historia común. No se trata tampoco de una mera tarea de apropiación por parte de las mujeres, sino más bien de tomar conciencia sobre el modo en el que ha sido elaborado el pensamiento y transformarlo críticamente para que las mujeres puedan servirse de su propia voz intelectual siendo interlocutoras válidas. Los métodos que utilizará para alcanzar este fin son:

1. Hermenéutica de la evaluación crítica: manifestar el proceso de interiorización y legitimación cultural y religiosa que se produce mediante la reproducción del sistema kyriárquico. El objetivo es descubrir el efecto que los textos tienen y han tenido sobre las mu- 
jeres. Trata de establecer una escala de valores elaborada a partir de las luchas emancipadoras por la supervivencia y la transformación. Persigue crear espacios radicalmente democráticos que tengan un horizonte teo-ético de la interpretación bíblica.

2. Hermenéutica de la memoria y la reconstrucción: supone un esfuerzo por recuperar, como patrimonio de las mujeres, la historia religiosa por ellas protagonizada y reivindicar su subjetividad histórica. También propone recontextualizar los textos bíblicos dentro de los actuales espacios sociopolíticos. La finalidad es que las religiones bíblicas dejen de proclamar textos utilizados para sostener la opresión, la invisibilidad, la sumisión o las opciones biopolíticas.

\section{EL MOMENTO IMAGINATIVO}

Desde su compromiso con la Biblia, Schüssler Fiorenza aboga por una transformación de nuestra imaginación literaria y teológica. Señala, como Martha. C. Nussbaum, que la literatura tiene la habilidad de representar las circunstancias y problemas específicos de las personas. Nos permite entender algo más a la gente que nos rodea, siendo un recurso especialmente valioso para la formación de la ciudadanía universal. Ella misma señala que las composiciones literarias pueden hacer que las personas invisibles sean visibilizadas «y eso, al menos, es un comienzo de justicia social».22

Esta teóloga feminista crítica propone crear espacios democráticos donde puedan generarse discursos críticos que evidencien la autoridad de las personas que son excluidas, para enzarzarse juntos, en un proceso deliberativo de interpretación bíblica. Schüssler Fiorenza aboga por la creación de espacios cooperativos basados en el reconocimiento. Para ello utiliza como herramientas:

1. Hermenéutica de la imaginación creativa: propone poner en marcha el recurso de la imaginación como herramienta para producir imaginarios religiosos diversos a los existentes que permitan cambios liberadores. Su interés es crear lugares donde la deliberación sea posible y produzca un tipo de conocimiento liberador.

2. Hermenéutica de la acción transformadora por el cambio: aspira a alterar las relaciones de dominación legitimadas e inspiradas por

22 Cf. M. C. Nussbaum, El cultivo de la humanidad. Una defensa de la reforma en la educación liberal. Barcelona: Paidós, 2005, pp. 117-148. 
las religiones bíblicas kyriarcales y opta comprometidamente por alcanzar un mundo diferente y más justo para todos.

Esta teóloga tiene en cuenta que nuestro saber se halla limitado por nuestro lenguaje e ubicación religiosa, social, económica, de clase, al mismo tiempo que por la retórica que utilizamos para narrarlas. Sabe que las diferencias, si son argumentadas racionalmente, pueden enriquecer el pensamiento común y mover nuestros horizontes de conocimiento. Por lo tanto, defiende que esta metodología hermenéutico-retórica y emancipadora es capaz de generar pensamiento democrático y modos liberadores que nos permitan imaginar y redefinir la Iglesia y, por qué no, también transformar algunos de los ámbitos que configuran nuestra sociedad.

\section{AlgunAS CONCLUSIONES}

La «desprivatización» de las religiones supone, entre otras consideraciones, que éstas ocupan un espacio en la esfera pública y que merecen ser reflexionadas críticamente debido a la amplia influencia que pueden ejercer sobre la sociedad civil, tal como han puesto de manifiesto las democracias deliberativas. ${ }^{23}$

En las distintas tradiciones religiosas las teólogas feministas han bebido, principalmente, de las abundantes y diversas corrientes filosóficas, psicológicas, antropológicas y sociológicas, feministas, post-feministas, las corrientes postcoloniales, las teorías gays, lesbianas y últimamente también de las teorías queers que están desarrollándose en Europa y en los países anglosajones. Algunas de las herramientas conceptuales que comparten estas diversas disciplinas y enfoques han permitido evidenciar la dimensión política de las mujeres, poner en cuestión cómo se ha ido produciendo su identidad y reclamar espacios deliberativos en los que poder participar democráticamente como sujetos de derechos.

La teología feminista se ha desarrollado como disciplina crítica de manera cada vez más amplia desde finales del siglo XX. La tarea de Elisabeth Schüssler Fiorenza ha contribuido decisivamente a ello gracias a su empeño en definir cómo la epistemología, la hermenéutica y la retórica han dado paso a lecturas interpretativas de los textos bíblicos sobre los que se ha construido la identidad, personal y social, de los y las creyentes. Su reflexión teológica ha elaborado una mirada crítica sobre el saber institucional eclesiástico, considerado autorizado, y sobre los procesos académicos que producen el conocimiento religioso.

23 A. Cortina, «Ciudadanía democrática: ética, política y religión. XIX Conferencias Aranguren», Isegoría , 44 (2011), pp. 13-55; P. J. Pérez Zafrilla, «La transformación de la Sociedad Civil: un proyecto en clave deliberativa». Contrastes. Revista Internacional de Filosofía. XIV (2009), pp. 199-215. 
Esta disciplina académica se sitúa como instancia crítica en el interior de las tradiciones y confesiones religiosas. Ha supuesto la irrupción de una mirada política con respecto al conocimiento institucional teológico autorizado y ha abierto este espacio a otras posibles lecturas de personas que reclaman ser consideradas como iguales.

Algunas de las consecuencias que se derivan de esta postura crítica que las religiones han de perseguir, según ha señalado la teología feminista católica, son el cambio identitario que proporciona la necesaria dimensión política de la fe pues las creencias, los sistemas de valores y verdades sobre las que se apoyan están sufriendo sacudidas que provocan un desplazamiento de sus horizontes de sentido. Otra es la transformación metodológica de la propia disciplina teológica que ve cómo sus herramientas cognoscitivas no son suficientes para comprender y actualizar el sentido de los textos bíblicos. Por ello, debe abrirse a otras disciplinas y compartir de modo transversal metodologías y paradigmas.

La búsqueda de modos teo-éticos de producción de conocimiento teológico permite que queden al descubierto las formas de ejercitar el poder que actualmente atraviesan a las instancias religiosas, sirviéndose de métodos de control y disciplinarios, que esclerotizan a las propias instituciones religiosas. De ahí que la tarea teológica feminista crítica haya incidido no solo en la producción misma de conocimiento sino también en cómo históricamente ha sido éste elaborado para determinar su incidencia sobre la identidad de los sujetos creyentes.

Las teologías feministas críticas están repensando también posibles formas retóricas éticas inscritas dentro de un marco social que permiten construir, sostener y diseñar confesiones religiosas en las que se reconozcan sus deberes y derechos como personas iguales en una comunidad de interpretación en la que todos y todas puedan ser reconocidos. Transformando entonces las relaciones de poder establecidas a partir de la concepción binaria de los sexos, géneros, etnias, preferencias sexuales o estatus sociales que dejan expuestas a la violencia y a la exclusión a muchas personas, arriesgándose a ser desprovistas de su condición de sujetos reconocidos. ${ }^{24}$

El campo de estudio ha quedado transformado y ampliado. La crítica establecida en el interior de las religiones es ahora también una oportunidad para dialogar con las distintas formas morales existentes en nuestras sociedades complejas, con las identidades sexuales, ${ }^{25}$ con los modos en los que se constituyen

24 J. Butler, Vida precaria. El poder del duelo y la violencia. Buenos Aires: Paidós, 2006. También ver J. Butler, «Performatividad, precariedad y políticas sexuales». AIBR. Revista de Antropología Iberoamericana, 4 (2009), pp. 321-336.

25 B. Preciado, Manifiesto contra-sexual. Práctica subversivas de identidad sexual. Madrid: Opera Prima 2002. 
las comunidades ${ }^{26} \mathrm{o}$ bien con las posibles encarnaciones de las democracias ${ }^{27}$ y sus necesarios fortalecimientos. Son temas que reclaman nuestra atención y exigen una profunda reflexión pues inciden directamente sobre nuestra vida común y ello no es algo menor.

\section{Bibliografía básica de Elisabeth Schüssler Fiorenza}

SCHÜSSLER FIORENZA, E.: En memoria de ella. Una reconstrucción teológicafeminista de los orígenes del cristianismo. Bilbao: Desclée de Brouwer, 1989.

, Bread Not Stone. The Challenge of Feminist Biblical Interpretation. Boston: Beacon Press, 1995.

,Discipleship of Equals. A critical Feminist Ekklēsia-logy of Liberation. Nueva York: Crossroad, 1998.

, Pero ella dijo. Prácticas feministas de interpretación bíblica. Madrid: Trotta, 1996.

,Cristología Feminista crítica. Jesús, Hijo de Miriam, Profeta de la Sabiduría. Madrid: Trotta, 2000.

, Apocalipsis. Visión de un mundo justo. Estella: Verbo Divino, 2003.

, Los caminos de la sabiduría. Una introducción a la interpretación feminista de la Biblia. Maliaño: Sal Terrae, 2004.

, The power of the Word. Scripture and the Rhetoric of Empire. Mineápolis: Fortress Press, 2007.

,Democratizing Biblical Studies. Toward an Emancipatory Educational Space. Louisville: Westminster John Knox Press, 2009.

,Transforming Visions. Explorations in Feminist The *logy. Mineápolis: Fortress Press, 2011.

NASRALLAH L. y SCHÜSSLER FIORENZA, E. (eds.): Prejudice and Christian Beginnings. Investigating Race, Gender, and Ethnicityin Early Christian Studies. Mineápolis: Fortress Press, 2009.

MontSerrat Escribano Cárcel es doctoranda en Filosofía en el Departamento de Filosofía del Derecho, Moral y Política, Facultad de Filosofía y Ciencias de la Educación de la Universitat de València

Lineas de investigación:

Hermenéutica crítica, teología feminista crítica y filosofía política

Dirección electrónica: monescri@hotmail.com

26 R. Esposito, Comunidad, inmunidad y biopolítica. Barcelona: Herder, 2009.

27 G. Agamben [et. al], Democracias en suspenso. Madrid: Casus Belli, 2010. 